\title{
Estrutura do pasto disponível e do resíduo pós-pastejo em pastagens de capim-cameroon e capim-marandu
}

\author{
Cláudia de Paula Rezende ${ }^{1}$, José Marques Pereira ${ }^{1}$, José Cardoso Pinto ${ }^{2}$, Augusto Magno \\ Ferreira Borges ${ }^{1}$, Joel Augusto Muniz ${ }^{3}$, Ivo Francisco de Andrade ${ }^{2}$, Antônio Ricardo Evangelista ${ }^{2}$ \\ ${ }^{1}$ CEPLAC - km 22 Rodovia Ilhéus - Itabuna, Caixa Postal 7 \\ 2 UFLA/DZO. Bolsista do CNPq. \\ ${ }^{3}$ UFLA/DEX. Bolsista do CNPq.
}

RESUMO - Avaliaram-se, em dois experimentos, as características estruturais e o teor de proteína bruta das forrageiras Pennisetum purpureum cv. Cameroon e Brachiaria brizantha cv. Marandu em pastagens submetidas a quatro taxas de lotação rotacionadas. No período das águas, as taxas de lotação impostas a ambas as pastagens foram de 3, 4, 5 e 6 novilhos/ha e, no período seco, de 2, 3, 4 e 5 novilhos/ha. Nos dois experimentos, o capim-cameroon apresentou maior massa de forragem total e massa de forragem verde, que decresceram com o aumento da desfolha imposta pelas taxas de lotação, principalmente no período seco. Nessa forrageira, o aumento da taxa de lotação comprometeu em maior intensidade a fração de matéria seca de lâmina foliar verde. No período das águas, as taxas de lotação que propiciaram maior oferta de massa seca de forragem total, forragem verde e fração de lâmina foliar foram as de 5 e 4 novilhos/ha, respectivamente, para os capins cameroon e marandu. No período seco, no entanto, os maiores valores obtidos para essas variáveis foram, respectivamente, de 4 e 3 novilhos/ha. As taxas de lotação não influenciaram o teor de proteína bruta das gramíneas, que foi maior no componente lâmina foliar verde da planta.

Palavras-chave: Brachiaria brizantha, forragem residual, matéria seca, oferta de forragem, Pennisetum purpureum, taxa de lotação

\section{Pasture structure and post-grazing herbage mass in pastures of elephantgrass cv. Cameroon and palisadegrass cv. Marandu}

\begin{abstract}
Two experiments were carried out to evaluate structural characteristics and crude protein concentration of Pennisetum purpureum cv. Cameroon and Brachiaria brizantha cv. Marandu under four rotational stocking rates. During the rainfall period, the studied stocking rates for both pastures were 3, 4, 5, and 6 steers/ha and in the dry period the stocking rates were 2, 3, 4, and 5 steers/ha. In both experiments, elephantgrass cv. Cameroon produced greater total herbage mass and green herbage mass, which decreased with the increase in defoliation as a result of the used stocking rates, mainly during the dry period. For elephantgrass pastures, the increase in stocking rate had a greater negative effect on the green leaf blade dry matter fraction. In the rainfall period, the stocking rates which promoted greater herbage allowance, green herbage mass, and leaf blade fraction were 5 steers/ha and 4 steers/ha for elephantgrass cv. Cameroon and marandugrass, respectively. In the dry period, greater values for these variables were obtained with 4 steers/ha and 3 steers/ha, respectively. Stocking rates did not influence crude protein concentration of the grasses, with leaf blade presenting higher concentration of this nutrient.
\end{abstract}

Key Words: Brachiaria brizantha, dry matter, forage allowance, Pennisetum purpureum, residual herbage mass, stocking rate

\section{Introdução}

As pastagens são a principal fonte de alimento para os bovinos e a forma mais prática e de menor custo. Assim, o estabelecimento e a manutenção de pastagens mais produtivas e de melhor qualidade têm sido obtidos por meio de manejos, que possibilitem o equilíbrio entre a produção das forrageiras e sua utilização, conseqüentemente, o rendimento animal.
A perenidade da pastagem depende da reconstituição da área foliar da planta forrageira quando o pastejo é realizado por meio da lotação intermitente e de sua manutenção quando sob lotação contínua; as respostas são determinadas por suas características genotípicas aliadas ao ambiente e ao manejo (Gomide, 1997). A freqüência e a intensidade das desfolhas são os principais parâmetros a serem considerados na definição do manejo da desfolha 
(Gomide et al., 1979). Nesse sentido, a quantificação da produtividade por meio de respostas relacionadas à persistência e aos mecanismos de rebrota de forrageiras sob pastejo é de suma importância na interação planta:animal (Rosseto, 2000).

De acordo com Silva \& Pedreira (1997), durante o período de crescimento das forrageiras exploradas em sistemas intensivos de produção de pastagens, as taxas de crescimento e de acúmulo de forragem podem ser elevadas, fazendo com que grandes produções de matéria seca sejam asseguradas, mas com risco de perda de qualidade, em decorrência de atrasos na colheita ou de pastejo mal executado. Nessas situações, o pastejo sob lotação rotativa é uma técnica que assegura o aproveitamento eficiente da produção, respeitando as exigências específicas e particulares de freqüência, intensidade e época de corte da planta forrageira.

Na avaliação da produção animal sob pastejo, deve-se considerar diversos aspectos, principalmente o desempenho animal, a capacidade de suporte da pastagem, a produção animal por hectare e a composição botânica da pastagem, bem como a estabilidade da cobertura vegetal. Assim, a produção animal por hectare consiste na estimativa da quantidade de forragem colhida incluindo as perdas de forragem por senescência e morte de folhas e perfilhos, as perdas por pisoteio e o resíduo de forragem, que caracteriza a quantidade de biomassa disponível (Gomide \& Gomide, 2001).

Objetivou-se avaliar a influência de taxas de lotação na estrutura do pasto disponível e residual e no teor de proteína bruta em pastagens de capim-elefante (Pennisetum purpureum Schum cv. Cameroon) e capim-marandu (Brachiaria brizantha (Hochst. ex A. Rich.) Stapf. cv. Marandu).

\section{Material e Métodos}

Foram conduzidos dois experimentos na Estação Experimental de Zootecnia do Extremo Sul (ESSUL), da CEPLAC, localizada em Itabela ( $\left(6^{\circ} 39^{\prime} \mathrm{S}\right.$ e $\left.39^{\circ} 30^{\prime} \mathrm{O}\right)$. A área está sob o domínio do ecossistema de Mata Atlântica e o clima local é uma transição entre os tipos Af e Am, segundo a classificação de Köppen, com precipitação anual de 1311 mm e temperatura média de $25^{\circ} \mathrm{C}$, sem estação seca definida (Figura 1). O solo é um Ultisol, cujas características químicas médias na camada de $20 \mathrm{~cm}$ de profundidade apresentaram os seguintes valores: $\mathrm{pH}$ em $\mathrm{H}_{2} \mathrm{O}=6,2 ; \mathrm{Al}=0,1 \mathrm{cmol}_{\mathrm{c}} / \mathrm{dm}^{3}$; $\mathrm{Ca}=2,6 \mathrm{cmol}_{\mathrm{C}} / \mathrm{dm}^{3} ; \mathrm{Mg}=0,4 \mathrm{cmol}_{\mathrm{C}} / \mathrm{dm}^{3} ; \mathrm{K}=0,2 \mathrm{cmol}_{\mathrm{C}} / \mathrm{dm}^{3}$; P disponível = 2,9 mg/dm .
A área experimental constou de 52 piquetes de capimelefante Cameroon e 52 piquetes de capim-marandu, cada um com área de $720 \mathrm{~m}^{2}$, totalizando $74.880 \mathrm{~m}^{2}$. Na implantação das pastagens aplicaram-se $1.000 \mathrm{~kg} /$ ha de calcário dolomítico e $80 \mathrm{~kg} / \mathrm{ha}$ de $\mathrm{P}_{2} \mathrm{O}_{5}$. Adubação de manutenção foi realizada na base de $160 \mathrm{~kg} / \mathrm{ha} \mathrm{de} \mathrm{N,} 60 \mathrm{~kg} / \mathrm{ha}$ de $\mathrm{P}_{2} \mathrm{O}_{5}$ e $120 \mathrm{~kg} / \mathrm{ha}$ de $\mathrm{K}_{2} \mathrm{O}$, utilizando como fontes desses nutrientes os fertilizantes uréia, superfosfato simples e cloreto de potássio, respectivamente.

Cada gramínea foi submetida a quatro taxas de lotação, em um sistema de lotação rotativa com 3 dias de pastejo e 36 dias de descanso. Foram conduzidos dois experimentos, um no período das águas (experimento 1) e o outro no período seco (experimento 2 ), que diferiram entre si quanto às taxas de lotação e ao número de ciclos de pastejo ocorridos. No período das águas as taxas de lotação foram 3, 4, 5 e 6 novilhos/ha por seis ciclos de pastejo intercalados. No período seco, as taxas de lotação empregadas foram 2, 3, 4 e 5 novilhos/ha, em três ciclos de pastejo.

O experimento no período das águas foi conduzido de 11/4/2001 a 28/6/2001 e 8/11/2001 a 13/4/2002, utilizando-se taxas de lotação 3, 4, 5 e 6 novilhos/ha. Essas taxas de lotação apenas foram mantidas por 2 ciclos, pois, com a diminuição das temperaturas (principalmente as noturnas), houve comprometimento no crescimento das forrageiras, no início do experimento no período seco (29/6/2001 a 24/10/2001), reduzindo, conseqüentemente, as taxas de lotação para 2, 3, 4 e 5 novilhos/ha.

Em cada ciclo de pastejo, foram feitas três amostragens da forragem antes e após o pastejo a cada 12 dias. Foram avaliados as massas de forragem e os teores de proteína bruta (PB).

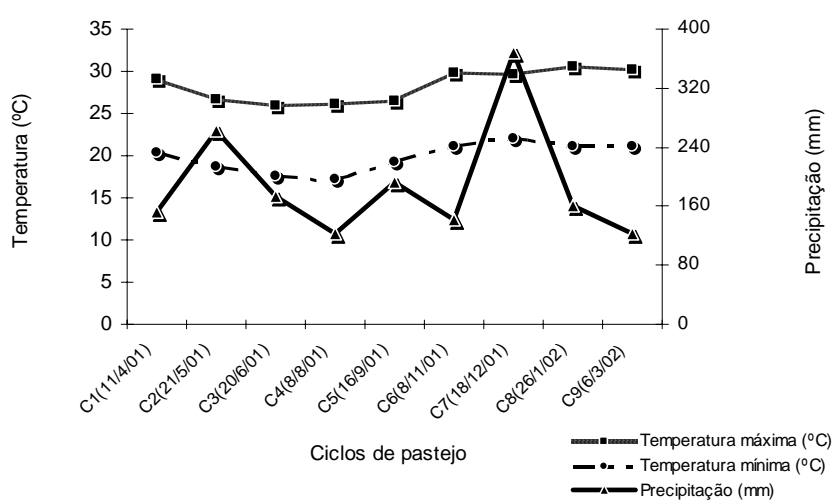

Figura 1 - Temperaturas máxima e mínima e distribuição da precipitação pluviométrica por ciclo de pastejo durante o período experimental. 
Na amostragem para estimar a massa de forragem, utilizou-se um quadrado de $1,0 \times 1,0 \mathrm{~m}$, lançado ao acaso seis vezes na área (formando uma amostra composta por piquete). Os cortes de forragem disponível e residual foram feitos 0,50 e 0,25 $\mathrm{m}$ de altura para o capim-elefante Cameroon e o capim-marandu, respectivamente. Essas alturas foram fixadas nos quadrados utilizados e a massas de forragem abaixo dessas alturas foram desconsideradas.

As amostras compostas da forragem colhida (antes e após o pastejo) foram pesadas e inicialmente retirou-se uma subamostra de aproximadamente $250 \mathrm{~g}$ da forragem constituída da mistura do material verde e material morto, para determinação da matéria seca de forragem total (MSFT). Retiraram-se também mais 2 kg desse material, que foi separado em fração de forragem senescente e verde (MSFM e MSFV); a fração verde foi separada ainda em fração de matéria seca de lâmina foliar e colmos verdes (MSLV e MSCV, respectivamente) para estimar a massa pelo método de cada um desses componentes da planta e determinar o teor de PB. As frações separadas foram pesadas e secas em estufa de ventilação forçada a $65^{\circ} \mathrm{C}$ até peso constante. Esse material foi triturado em moinho do tipo Wiley, em peneira de $1 \mathrm{~mm}$ de diâmetro, para as determinações de PB pelo método Kjeldahl e posterior determinação do teor de MS.

Utilizaram-se machos da raça Nelore com peso vivo médio de $280 \mathrm{~kg}$, colocados na área experimental 30 dias antes do início da coleta de dados (período pré-experimental), para se ajustarem às condições dos piquetes (cercas elétricas, área de descanso, bebedouros e saleiros).

Ao término do período pré-experimental, os animais foram pesados após jejum prévio de 15 horas e retornaram aos piquetes. As amostragens de massa de forragem sempre precediam a entrada dos animais nos piquetes. Ao final de cada ciclo de pastejo (39 dias), os animais eram pesados após jejum de 15 horas e retornavam à área experimental.

O delineamento utilizado foi blocos ao acaso com repetição no tempo, correspondente aos ciclos de pastejo, com os tratamentos dispostos no esquema de parcelas subdivididas, com as duas gramíneas ocupando as parcelas e as quatro taxas de lotação, as subparcelas, de acordo com o modelo abaixo:

$$
\mathrm{Y}_{\mathrm{ij}(\mathrm{k})}=\mu+\mathrm{G}_{\mathrm{i}}+\mathrm{B}_{\mathrm{j}}+\mathrm{e}_{(\mathrm{ij})}+\mathrm{T}_{\mathrm{k}}+\mathrm{GT}_{(\mathrm{ik})}+\mathrm{BT}_{(\mathrm{jk})}+\mathrm{e}_{(\mathrm{ij}) \mathrm{k}}
$$

em que: $\mathrm{Y}_{\mathrm{ij}(\mathrm{k})}=$ valor da observação da gramínea i na taxa de lotação $\mathrm{k}$, no ciclo j; $\mu$ = média geral (constante inerente a todas as observações); $G_{i}=$ efeito da gramínea i, sendo $\mathrm{i}=1,2 ; \mathrm{B}_{\mathrm{j}}=$ efeito do bloco (ciclo de pastejo) $\mathrm{j}$, em que $\mathrm{j}=1,2,3,4,5$ e 6 para experimento 1 e $\mathrm{j}=1,2$ e 3 para experimento 2; e $\mathrm{e}_{(\mathrm{ij})}=$ erro experimental associado às parcelas com distribuição normal, média 0 e variância $\sigma_{\mathrm{a}}{ }^{2}$; $\mathrm{T}_{\mathrm{k}}=$ efeito da taxa de lotação $\mathrm{k}$, em que $\mathrm{k}=1,2,3$, 4; $\mathrm{GT}_{(\mathrm{ik})}=$ interação gramínea $\mathrm{i} \times$ taxa de lotação $\mathrm{k} ; \mathrm{CT}_{(\mathrm{jk})}=$ interação ciclo de pastejo $\mathrm{j} \times$ taxa de lotação $\mathrm{k} ; \mathrm{e}_{(\mathrm{ij}) \mathrm{k}}=$ erro experimental associado às subparcelas com distribuição normal, média 0 e variância $\sigma^{2}$.

Para atender às exigências desse modelo estatístico, admitiu-se que os efeitos dos fatores envolvidos no modelo foram aditivos, os tratamentos tiveram variâncias homogêneas e os erros eram independentes, com distribuição normal.

Os dados foram submetidos à análise de variância e ao teste de homogeniedade de variância, utilizando-se o procedimento ANOVA (para dados balanceados) dos recursos do software estatístico SAS (Statistical Analysis System, 1996). As comparações de médias foram feitas utilizando-se o teste Tukey a 5\% de significância. As análises de regressão foram realizadas considerando variáveis independentes as taxas de lotação, pelo software estatístico 'Sistema de Análise Estatística para Dados Balanceados (SISVAR ) de acordo com Ferreira (1998).

\section{Resultados e Discussão}

No período das águas, tanto para gramínea como para taxa de lotação em relação à massa de forragem, houve diferenças significativas pelo teste de F a 5\% de significância. Apesar de não terem sido observadas diferenças significativas para a interação taxa de lotação e gramíneas, para as variáveis em estudo, foi realizado o desdobramento da interação com o objetivo de avaliar o efeito das taxas de lotação por gramínea.

No período das águas, o capim-elefante 'Cameroon' apresentou maior massa de forragem em comparação ao capim-marandu (Figura 2). Em trabalhos conduzidos por Santos et al. (2003), o capim-marandu também apresentou produções inferiores à dos cultivares Pioneiro, Mott, Mombaça e Tanzânia. Segundo Silva et al. (1996), o potencial produtivo das forrageiras pode variar conforme a espécie, o cultivar, a freqüência e altura de corte, a disponibilidade de água, luz e temperatura, a eliminação do meristema apical e a área foliar residual, entre outros.

A massa de forragem foi inversamente proporcional ao aumento das taxas de lotação (Figura 2). As reduções no capim-elefante Cameroon foram de 33, 31, 21, 38 e 41\% para as massas de MSFT, MSFV, MSLV, MSCV, MSFM, respectivamente, e corresponderam à menor e maior taxas 
de lotação em estudo (Figura 2). No capim-marandu, no entanto, as reduções foram superiores e se mantiveram em torno de 40, 40, 31, 49 e 40\% para as massas de MSFT, MSFV, MSLV, MSCV e MSFM, respectivamente (Figura 2). Esses resultados podem ser justificados pelo fato de o capimelefante mais produtivo que o capim-marandu e ambos terem sido submetidos a uma mesma taxa de lotação.

No período seco, houve diferenças $(\mathrm{P}<0,01)$ na massa de forragem entre as gramíneas, com exceção da MSLV, das taxas de lotação $(\mathrm{P}<0,01)$ e da interação taxa de lotação $\times$ gramínea $(\mathrm{P}<0,05)$.

Nesse período, com o aumento das taxas de lotação, houve decréscimo na massa de forragem, que foi mais acentuado no capim-elefante (Figura 3). As reduções no capim-elefante Cameroon foram em torno de 49, 55, 48, 61
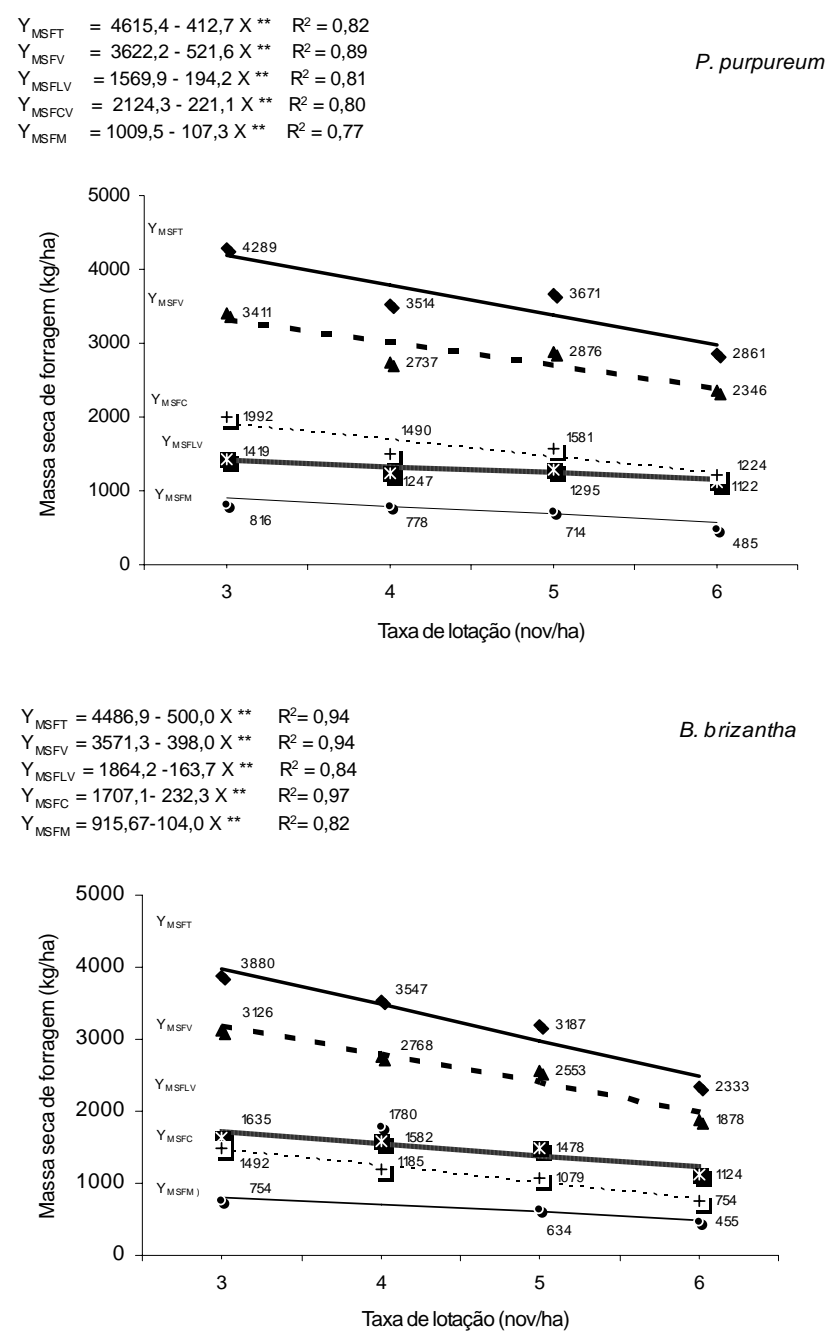

Figura 2 - Massas de matéria seca de forragem total (MSFT), de forragem verde (MSFV), de lâmina foliar verde (MSLV), de colmo verde (MSCV) e de forragem morta (MSFM) de $P$. purpureum e $B$. brizantha em taxas de lotação crescentes (Período das águas). e $26 \%$ e para o capim-marandu, 32, 39, 37, 33 e 19\% para massas de MSFT, MSFV, MSLV, MSCV e MSFM, respectivamente, comparando-se menor e maior taxas de lotação (Figura 3), resultados opostos aos obtidos durante o período das águas. Entre as duas gramíneas, os valores obtidos para massa de forragem em capim-elefante Cameroon foram superiores e/ou similares aos de capim-marandu, exceto na taxa de lotação de 3 novilhos/ha, cuja massa de MSLV foi de $1064,3 \mathrm{~kg}$ /ha para o capim-elefante e 1.248,6 kg/ha para o capim-marandu (Figura 3).

Os dados referentes à massa de forragem do material morto, os quais foram obtidos subtraindo-se da MSFT a MSFV, forneceram subsídios para estimativa das perdas de forragem durante o pastejo, em razão do aumento das taxas de lotação. Logo, as menores taxas de lotação propiciaram

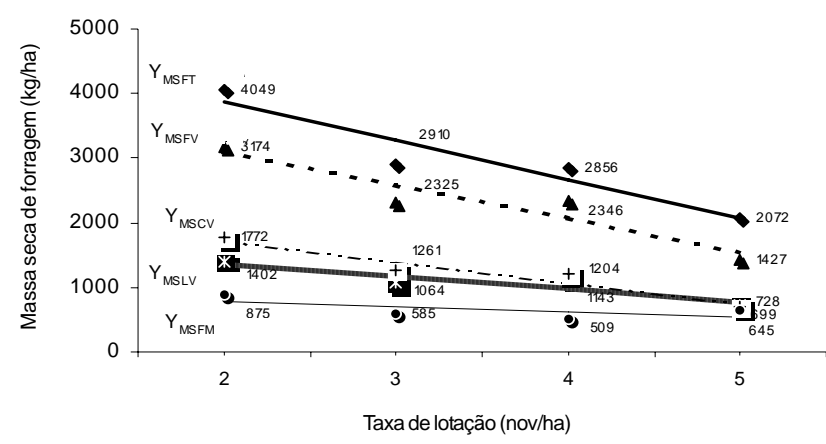

$\begin{array}{ll}Y_{\text {MSFT }}=2955,0-278,0 X^{\star \star} & R^{2}=0,92 \\ Y_{\text {MSFV }}=2092,4-233,0 X^{\star \star} & R^{2}=0,79 \\ Y_{\text {MSLV }}=1427,6-168,3 X^{\star \star} & R^{2}=0,84 \\ Y_{\text {MSCV }}=664,75-64,01 X^{n s} & R^{2}=0,91 \\ Y_{\text {MSFM }}=1427,6-168,3 X^{n s} & R^{2}=0,84\end{array}$

B. brizantha

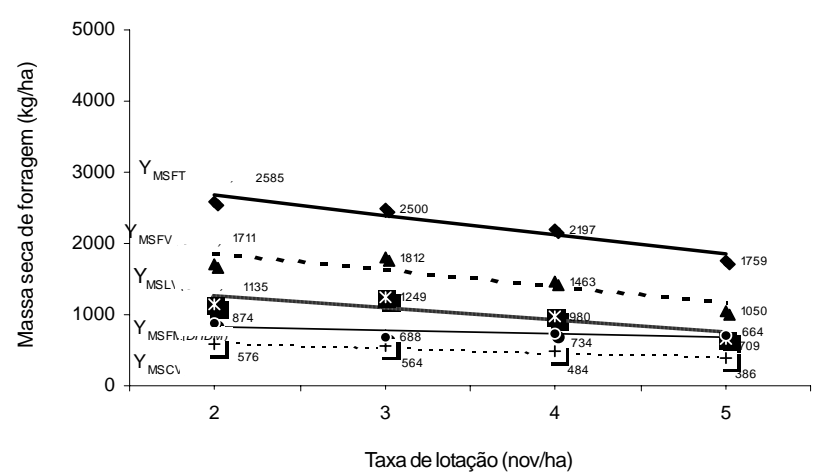

Figura 3 - Massas de matéria seca de forragem total (MSFT), de forragem verde (MSFV), de lâmina foliar verde (MSLV) de colmo verde (MSCV) e de forragem morta (MSFM) de $P$. purpureum e $B$. brizantha em taxas de lotação crescentes (Período seco) 
maiores perdas de forragem, principalmente por senescência do material não consumido pelos animais.

As ofertas de forragem foram estimadas nos dois períodos. No período das águas, para as taxas de lotação 3, 4, 5 e 6 novilhos/ha, as ofertas de forragem foram, respectivamente, iguais a 7,$2 ; 4,9 ; 3,9$ e $2,6 \%$, com base na MSFV, e 3,5; 2,5; 2,0 e 1,4\%, com base na MSLV. As taxas de lotação mais altas proporcionaram desfolhas mais intensas e resultaram em menores massas de forragem. $\mathrm{Na}$ lotação de 6 novilhos/ha obtiveram 2.112 kg/ha de MSFV, a uma oferta de forragem de 2,6 kg de MS/100 kg de PV animal/dia, com 53\% de lâminas foliares verdes.

Em capim-elefante 'Mott', Silva et al. (1994) observaram que a pressão baixa resultou em maior densidade de forragem, maior quantidade de material morto e baixa relação folha/colmo, enquanto, na pressão alta, houve maior relação folha/colmo, pouco material morto e predominância de folhas verdes. A porcentagem de folhas na pressão baixa foi de $56 \%$ e na alta, de $62 \%$.

Resultados semelhantes foram obtidos por Marcelino et al. (2006) em capim-marandu, que relataram que o aumento no intervalo e intensidade de desfolhações proporcionaram maiores quantidades de pseudocolmo e material morto, resultando em forragem de mais baixo valor nutritivo e maiores perdas de forragem.

Segundo Blaser (1994), as interações dos conhecimentos de pressão de pastejo e resíduo, dentro de determinados

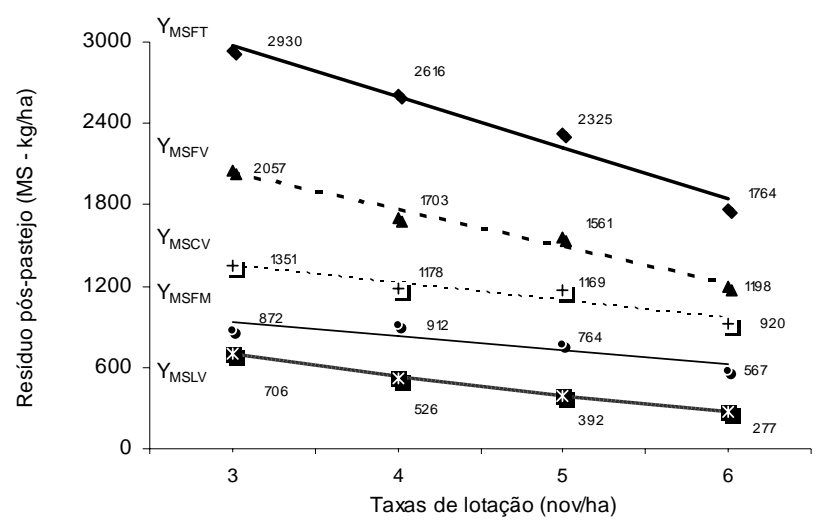

Figura 4 - Resíduo pós-pastejo de massa seca de forragem total (MSFT), de forragem verde (MSFV), de lâmina foliar verde (MSLV), de colmo verde (MSCV) e forragem morta (MSFM) das gramíneas em taxas de lotação crescentes (Período das águas). níveis de massa de forragem, poderão garantir a redução nas perdas de forragem e o máximo aproveitamento da forragem disponível pelo animal.

No resíduo pós-pastejo, durante o período das águas, foram encontradas diferenças significativas para gramíneas e taxas de lotação $(\mathrm{P}<0,01)$. No entanto, o resíduo póspastejo só diferiu $(\mathrm{P}<0,01)$ nas duas gramíneas para as frações lâmina foliar verde (MSLV) e colmos verdes (MSCV). Não houve interação taxa de lotação × gramínea.

Durante o período seco, também foi avaliado o resíduo pós-pastejoe houve diferenças significativas entre gramíneas $(\mathrm{P}<0,05)$ e taxa de lotação $(\mathrm{P}<0,01)$. A interação taxa de lotação e gramíneas apenas foi significativa para as frações MSFV e MSCV $(\mathrm{P}<0,05)$.

Os resíduos pós-pastejo nas duas gramíneas, no período das águas e no período seco, decresceram com o aumento da taxa de lotação (Figuras 4 e 5).

No período das águas, assim como para a massa seca de forragem no pré-pastejo (Figura 2), as maiores massas de resíduos também ocorreram nas menores taxas de lotação, uma vez que nessas taxas as desfolhas não foram intensas, restando elevada quantidade de forragem que não foi consumida pelos animais (Figura 4).

Comparando a massa seca média de forragem no prépastejo (Figura 2) e no pós-pastejo (Figura 4), no período das águas, constatou-se que com o pastejo houve redução de 29, 40, 65 e 14\% para os componentes MSFT, MSFV,

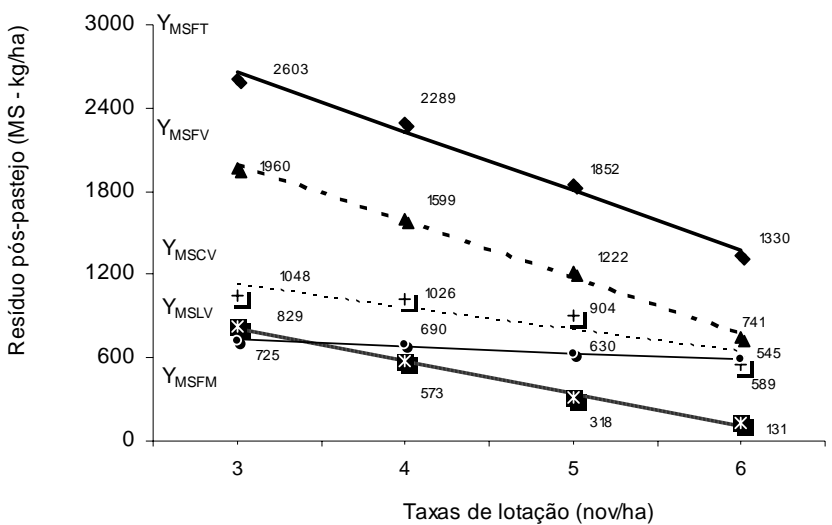

Figura 5 - Resíduo pós-pastejo de massa seca de forragem total (MSFT), de forragem verde (MSFV), de lâmina foliar verde (MSLV), de colmo verde (MSCV) e forragem morta (MSFM) das gramíneas em taxas de lotação crescentes (Período seco). 
MSLV, MSCV, respectivamente, o que torna notório que essa redução foi maior nas folhas verdes.

No período seco, como foi discutido nas condições do período das águas, considerando a média geral da massa de forragem no pré-pastejo (Figura 3) e pós-pastejo (Figura 5), o pastejo promoveu reduções de 20, 29 e 67\% das frações MSFT, MSFV e MSLV, enquanto para MSCV houve aumento em torno de 3\%. Essas reduções, exceto para folhas verdes, foram inferiores às obtidas no período das águas, provavelmente influenciadas pelas condições climáticas.

As condições menos favoráveis de temperatura, precipitação e luminosidade comprometeram a massa de forragem. Por esse motivo, as taxas de lotação foram reduzidas, o que, provavelmente, favoreceu maior sobra de material vegetativo, ou seja, maior quantidade de resíduo póspastejo. Possivelmente, o fato de se ter mantido um nível mais alto de resíduo nessas condições evitou danos mais drásticos às plantas, evitando o comprometimento com os pastejos sucessivos.

As folhas remanescentes no resíduo participam e/ou garantem a rebrota vigorosa da planta pastejada, interferindo na quantidade de MS acumulada e, conseqüentemente, no aproveitamento da forragem produzida por meio da redução nos níveis de perdas pelo pastejo. Além desses aspectos, a quantidade de folhas remanescentes na planta pastejada indica o nível de pressão de pastejo e a supressão da seletividade do pastejo exercida pelo animal, que prefere folhas a colmos. Assim, se há poucas folhas remanescentes, pode-se inferir que a pressão de pastejo foi alta e que, conseqüentemente, a seletividade foi mínima (Hillesheim \& Corsi, 1990). Segundo os autores, para reduzir as perdas de forragem em capim-elefante deve-se promover a máxima produção de massa seca de forragem verde (MSFV), com alta proporção de folhas, reduzindo a altura da planta, forma mais eficiente de se promover o máximo crescimento da planta e induzir o perfilhamento lateral.

No período das águas, com o aumento da taxa de lotação houve redução de 26\% na MSLV (Figura 2), que aumentou após o pastejo para 60\% (Figura 4), resultados superiores aos obtidos para as demais frações estudadas. Nas taxas de lotação de 3, 4, 5 e 6 novilhos/ha, respectivamente, o pastejo propiciou redução de 37, 38, 43 e 43\% na fração MSFV e de 54, 63, 72 e 75\% na fração MSLV.

A redução da oferta de forragem com oaumento da intensidade de desfolha pelos animais determina menores ganhos de peso médio diário e sensíveis reduções nos ganhos por área, entretanto, na manutenção de massa de forragem residual em limites adequados, garante a estrutura da pastagem e a qualidade da forragem em patamares favoráveis ao desempenho animal (Almeida et al., 2000; Martha Jr. et al., 2004; Barbosa et al., 2006).

No período seco, as taxas de lotação mais baixas também foram as que propiciaram maior resíduo pós-pastejo (Figura 5). Neste estudo, o pastejo propiciou redução de aproximadamente 20, 23, 36 e 40\% na fração de MSFV, respectivamente, nas taxas de lotação de 2, 3, 4 e 5 novilhos/ha. Na fração MSLV, a redução foi de 41, 50, 70 e $81 \%$, respectivamente, nas lotações 2, 3, 4 e 5 novilhos/ha. Com o aumento da taxa de lotação, o decréscimo na quantidade de resíduo mais acentuado para a fração MSFV, sobretudo pela presença da fração folha verde que participa desse material.

No período das águas, as gramíneas diferiram $(\mathrm{P}<0,05)$ entre si apenas quanto aos teores de $\mathrm{PB}$ nas frações MSFV e MSLV. No capim-elefante Cameroon, o teor de PB foi de 8,6\% e 11,3\% e no capim-marandu de 7,9 e 10,3\% nas frações MSFV e MSLV, respectivamente. Nas frações MSFT e MSCV, os teores médios foram 7,2 e 5,4\%, respectivamente, e os teores de PB não diferiram entre as taxas de lotação, ficando entre 6,7 e 7,7\%; 8,0 e 8,8\%; 10,7 e 10,8\%, e 5,2 e 5,8\% para MSFT, MSFV, MSLV, e MSCV, respectivamente, nas taxas de lotação de 3 a 6 novilhos/ha.

Nas condições de menores temperaturas e precipitações (período seco), não foram determinadas diferenças significativas para teores de PB nas frações MSFT, MSLV e MSCV, nas quais os teores médios foram de 9,5; 13,9 e $6,5 \%$, respectivamente. O capim-marandu superou o capim-elefante Cameroon em PB apenas na fração MSFV, com um teor de PB de $11,8 \%$ comparado ao de $10,6 \%$ de PB obtido no capim-elefante Cameroon. Isso pode ter ocorrido porque o capim-elefante, nestas condições, apresentou uma maior percentagem de colmos verdes e, como já conhecido, os colmos têm menor qualidade do que as folhas. No período seco, as taxas de lotação influenciaram $(\mathrm{P}<0,05)$ apenas os teores de $\mathrm{PB}$ na MSFV, que foram de 10,$0 ; 11,1 ; 11,3$ e $12,3 \%$ para as lotações de 2 , 3, 4 e 5 animais/ha, respectivamente. A lotação de 5 novilhos/ha foi a que proporcionou o maior teor de PB. Nas frações MSFT, MSLV e MSCV, os teores de PB não diferiram significativamente entre as taxas de lotação (médias de 9,5; 13,9 e 6,7\%).

No período das águas, os teores de PB nos resíduos pós-pastejo das frações estudadas diferiram entre as gramíneas $(\mathrm{P}<0,05)$, com exceção do componente folha (MSLV). Os teores de PB no capim-elefante Cameroon foram 4,9; 5,7 e 4,4\% nas frações MSFT, MSFV e MSCV, resultados inferiores aos obtidos no capim-marandu que 
apresentou 5,4; 6,6 e 4,7\%de PB nessas frações. Na fração MSLV o teor médio foi de 8,9\%. A taxa de lotação ocasionou diferenças significativas $(\mathrm{P}<0,05)$ apenas no material verde (MSFV), cujos valores obtidos foram de 6,5; 6,3; 5,9 e 5,7\% de PB, para as lotações de 3, 4, 5 e 6 novilhos/ha, respectivamente. Para as frações MSFT, MSLV e MSCV, os teores médios foram de 5,2; 8,9 e 4,5\% de PB.

No período seco, os teores de PB nas gramíneas no resíduo pós-pastejo diferiram em todas as frações $(\mathrm{P}<0,05)$, com exceção da fração MSCV, que apresentou teor médio de 5,3\%. Os teores de PB nas frações MSFT, MSFV e MSLV do capim-marandu foram 7,5; 8,6 e 12,3\%, superiores aos teores de 5,9; 6,8 e 10,8\% obtidos no capim-elefante Cameroon. A interação taxa de lotação $\times$ gramíneas foi significativa apenas na fração MSLV $(\mathrm{P}<0,05)$. Os teores de PB foram 11,0; 12,6; 12,2 e 13,3\% para o capim-marandu e 9,7; 11,1; 14,3 e 7,9\% para o capim-elefante Cameroon nas lotações de 2, 3, 4 e 5 animais/ha, respectivamente. A lotação de 4 novilhos/ha foi a que apresentou o maior teor de PB $(14,3 \%)$ na MSLV de capim-elefante Cameroon, ao passo que no capim-marandu foi a de 5 novilhos/ha (13,3\%).

Tanto na forragem disponível quanto no resíduo póspastejo, os teores de PB obtidos nas condições de menores precipitação e temperatura, características do período seco, foram superiores aos obtidos no período das águas, quando as condições foram mais favoráveis ao crescimento e desenvolvimento das plantas. Uma das possíveis justificativas desses resultados seria a de que no período seco, tanto na forragem em oferta como no resíduo, a porcentagem de folhas no material verde (MSFV) foi maior. As porcentagens de folhas verdes na MSFV do período das águas foram 47, 51, 51 e 53\%, respectivamente, para as lotações 3, 4, 5 e 6 novilhos/ha; já no período seco, foram 50, 56, 56 e 56\%, respectivamente, para as lotações 2, 3, 4 e 5 novilhos/ha. $\mathrm{O}$ mesmo comportamento foi observado no resíduo póspastejo, quando as porcentagens de folhas no material verde foram 34, 31, 25 e 23\% nas lotações 3, 4, 5 e 6 novilhos/ha e 44, 36, 26 e 18\% nas lotações 2, 3, 4 e 5 novilhos/ha, nos períodos das águas e seco, respectivamente. Logo, nas condições de seca, com o aumento da intensidade de desfolha provocada pelo aumento da taxa de lotação, a planta respondeu emitindo mais folhas, mesmo que menores e mais estreitas, além de colmos pouco desenvolvidos.

As folhas são importantes na ecologia e economia de sistemas de pastagem, pois produzem os assimilados necessários para o crescimento e a manutenção da planta, assim como o alimento para os organismos heterotróficos que prosperam em ecossistema do pastejo, incluindo os bovinos. Conseqüentemente, a habilidade das forrageiras em manter a produção foliar sob desfolhação periódica é essencial para a manutenção de uma pastagem sustentável e para a sobrevivência das plantas pastejadas (Schnyder et al., 1999).

Segundo Gontijo Neto et al. (2006), o tempo de pastejo, a massa de matéria seca de folhas, a relação folha/colmo e a altura do dossel são altamente correlacionados ao consumo de forragem podem ser utilizados no desenvolvimento de modelos de predição de consumo de forragem ou desempenho animal em pastejo.

\section{Conclusões}

Com o aumento na taxa de lotação nas pastagens, diminuem as massas de forragem disponível e residual, efeito que difere entre as duas gramíneas conforme a época do ano. As taxas de lotação influenciam na menor disponibilidade de forragem disponível e residual do capim-marandu. As taxas de lotação não afetam o teor de proteína bruta, que varia de acordo com a espécie forrageira, as frações de forragens e a época do ano. A massa seca de lâmina foliar verde é o componente de maior participação na biomassa total do pasto.

\section{Literatura Citada}

ALMEIDA, E.X.; MARASCHIN, G.E.; HARTHMANN, O.E.L. et al. Oferta de forragem de capim-elefante Anão 'Mott' e o rendimento animal. Revista Brasileira de Zootecnia, v.29, n.5, p.1288-1295, 2000.

BARBOSA, M.A.A.F.; NASCIMENTO JR., D.; CECATO, U. Dinâmica da pastagem e desempenho de novilhos em pastagem de capim-tanzânia sob diferentes ofertas de forragem. Revista Brasileira de Zootecnia, v.35, n.4, p.1594-1600, 2006.

BLASER, R.E. Manejo do complexo pastagem-animal para avaliação de plantas e desenvolvimento de sistemas de produção de forragem. In: PEIXOTO, A.M.; MOURA, J.C.; FARIA, V.P. (Eds.). Pastagens: fundamentos da exploração racional. 2.ed. Piracicaba: Fundação de Estudos Agrários Luiz de Queiroz, 1994. p.279-335.

FERREIRA, D.F. Sistema de análise estatística para dados balanceados (SISVAR). Lavras: UFLA/DEX, 1998. (CR-ROM).

GOMIDE, J.A. O fator tempo e o número de piquetes do lotação rotativa. In: PEIXOTO, A.M.; MOURA, J.C.; FARIA, V.P. (Eds.). SIMPÓSIO SOBRE MANEJO DA PASTAGEM, 14. 1997, Piracicaba. Anais... Piracicaba: Fundação de Estudos Agrários Luiz de Queiroz, 1997. p.253-272.

GOMIDE, J.A.; GOMIDE, C.A.M. Utilização e manejo de pastagens. In: PEDREIRA, C.G.S.; SILVA, S.C. (Eds.). A produção animal na visão dos brasileiros. Piracicaba: Fundação de Estudos Agrários Luiz de Queiroz, 2001. p.808-825.

GOMIDE, J.A.; OBEID, J.A.; RODRIGUES, L.R.A. Fatores morfofisiológicos de rebrota do capim-colonião (Panicum maximum Jacq.). Revista da Sociedade Brasileira de Zootecnia, v.8, n.4, p.532-560, 1979.

GONTIJO NETO, M.M.; EUCLIDES, V.P.B.; NASCIMENTO JR., D et al. Consumo e tempo diário de pastejo por novilhos nelore em pastagem de capim-tanzânia sob diferentes ofertas de forragem. Revista Brasileira de Zootecnia, v.35, n.1, p.60-66, 2006. 
HILLESHEIM, A.; CORSI, M. Capim elefante sob pastejo. II. Fatores que afetam as perdas e utilização de matéria seca. Pesquisa Agropecuária Brasileira, v.25, n.9, p.1233-1246, 1990.

MARCELINO, K.R.A.; NASCIMENTO JR., D.; DA SILVA, S. et al. Características morfogênicas e estruturais e produção de forragem do capim-marandu submetido à intensidade e freqüências de desfolhação. Revista da Sociedade Brasileira de Zootecnia, v.35, n.6, p.2243-2252, 2006.

MARTHA JR., G.B.; CORSI, M.; BARIONI, L.G. et al. Intensidade de desfolha e produção de forragem de capim-tanzânia irrigado na primavera e no verão. Pesquisa Agropecuária Brasileira, v.39, n9, p.927-936, 2004.

ROSSETO, F.A.A. Desempenho agronômico de pastagens de capim elefante cv. Guaçu (Pennisetum purpureum Schum) e capim Tanzânia (Panicum maximum Jacq.) em sistemas de produção de leite. Piracicaba: Escola Superior de Agricultura Luiz de Queiroz, 2000. 144 p. Dissertação (Mestrado em Ciência Animal e Pastagem) - Escola Superior de Agricultura Luiz de Queiroz, 2000.

STATISTICAL ANALYSIS SYSTEM - SAS. User's guide: Statistics.Version 6. 11 System for Windows Edition. Cary: SAS Institute, 1996. (CD-ROM).
SCHNYDER, H.; SCHÄUFELE, R.; VISSER, R. et al. An integrated view of $\mathrm{C}$ e $\mathrm{N}$ uses in leaf growth zones of defoliated grasses. In: SIMPÓSIO INTERNACIONAL: GRASSLAND ECOPHISIOLOGY AND GRAZING ECOLOGY, 1999, Curitiba. Anais... Curitiba: Universidade Federal do Paraná, 1999. p.109-133.

SANTOS, M.V.F.; DUBEUX, J.C.B.; SILVA, M.C. et al. Produtividade e composição química de gramíneas tropicais na Zona da Mata de Pernambuco. Revista Brasileira de Zootecnia, v.32, n.4, p.821-827, 2003.

SILVA, D.S.; GOMIDE, J.A.; FONTES, C.A.A. Pressão de pastejo em pastagem de capim elefante 'anão'. 1. Estrutura e disponibilidade de pasto. Revista da Sociedade Brasileira de Zootecnia, v.23, n.2, p.249-257, 1994.

SILVA, S.C.; FARIA, V.P.; CORSI, M. Sistema intensivo de produção de leite em pastagem de capim elefante do Departamento de Zootecnia da ESALQ. In: CONGRESSO BRASILEIRO DE GADO LEITEIRO, 2., 1995, Piracicaba. Anais... Piracicaba: Fundação de Estudos Agrários Luiz de Queiroz, 1996. p.97-122.

SILVA, S.C.; PEDREIRA, C.G.S. Princípios de ecologia aplicados ao manejo da pastagem. In: SIMPÓSIO SOBRE ECOSSISTEMA DE PASTAGENS, 3., 1997, Jaboticabal. Anais... Jaboticabal: FUNEP, 1997. p.1-62. 